\title{
Playing the Game of Colorism
}

\author{
Shane E. Heckstall
}

Sociologist: CCSU

(860) 670-0415

\section{Doi:10.5901/jesr.2013.v3n2p31}

\begin{abstract}
:
The purpose of this research is to first prove "colorism" is a problem and whether or not it is significant at a predominantly white collegiate institution. The sample was a mix of 12 white and non-white students at a predominantly white college campus. Each participant was given a short questionnaire with six questions and the data was collected on an anonymous basis. Data was analyzed for patterns and implications and the results generally show that $41 \%$ experienced colorism, approximately $16 \%$ did not experience colorsim nor think it was a problem, while approximately $16 \%$ were non-white and the majority of respondents were at least "aware" of colorism.
\end{abstract}

\section{Introduction}

1. A black student walks into a traditionally white fraternity and immediately feels something. What is it? And why?

2. Females of lighter/fair complexion get more attention at all the social gatherings on campus. What lies behind this?

3. A black student seems to get along with various different white people and other black students see that individual as unusual. Why? What enables a black student to adapt to a predominantly white collegiate institution?

4. "She's dark-skinned, but..." "He's really light-skinned, so..." "He's white, but..." "I'm too ghetto (black), that's why..." How do these sentences end? And why?

5. Or why are black students, on their own school campus, constantly asked: "do you go here?"

The Black-White Achievement Gap is a real and complex issue that appears to correlate to Black/minority students who struggle to achieve based on disciplinary problems, lack of academic preparation, and even insufficient natural intelligence in comparison to other groups. Furthermore, within the Black-White Achievement Gap, there is limited research, which specifically examines the student to gain a better understanding of his/her experience. The rationale is that although the Black-White Achievement Gap has numerous reasons, it is important to look at the social identity of experience of those minority students and begin to infer any problems linked to student achievement. In this case, we are identifying a social issue among minority students that intuitively, this issue affects the self-esteem, self-efficacy, etc. of the student and ultimately impacts the student's achievement. In this action research, we focus more on identifying the issue and whether it is a significant problem. African-American history shows the effects of a social issue named, colorism both blatantly and at times subconsciously. From documents of Willie Lynch to modern films of mass production, there is a piece of cultural psychology that correlates to colorism among African-Americans. Such things as beauty, perceived socio-economic status, criminal inclination, education level and other attributes are self-ascribed and put upon African-Americans at times intentionally or unintentionally based on skin tone. Social issues actually does impact students; this is evidenced by a plethora of common knowledge that victims of bullying are affected in school as well as the LBGQT community. Hence the purpose of this study is to examine one social issue being racism, but even more specific within such is colorism and how this affects students. Moreover, this action research is aimed to discover if colorism is existence in the context and whether 
respondents feel that colorism is a significant problem. It is important to segue into how other researchers have defined colorism, its history, its implied effects and the larger dynamic between minorities and whites.

Start with one significant way that we socialize and socially interpret one another; Norman Denzin's theory of symbolic interactionism suggests that our "self" is built of multiple layers that each have a unique function which operate independently and interdependently. Denzin (1992) believes there are six layers of "self" operating in flux during a social interaction:

First there is the phenomenological self, the inner stream of consciousness of the person in the social situation. Secondly, the interactional self is the self that is presented and displayed to another in a concrete sequence of action. Thirdly, the linguistic self is evident when a person fills in the empty personal pronouns (e.g. I, me) with personal biographical and emotional meanings.

Next, the material self encompasses the self as a material object, which consists of all the person calls his or hers at a particular moment in time. Also there is an ideological self, which extends to the broader cultural and historical meanings that surround the definition/perception of the individual in a particular group or social situation. Lastly, there is the self as desire, which is the mode of self experience that desires its own fulfillment through the flesh, sexuality and the bodily presence of others.

When these six layers of self are in flux or in negotiation during a social interaction, the dominant or perceived self can have a substantial impact on the identity of the individual. For example, if the interactional self prevails, the individual will fall into a role and interact in a performed behavior. This is evidenced by the power of social norms; when a person walks into a fast-food restaurant, there is a typical interaction that transpires and really manifests the nature of one's interactional self. Or similarly, when the ideological self supersedes all other selves it can affect both the behavior of the individual performing and how the individual is perceived because larger cultural and historical meanings/implications have taken precedence. This is evidenced by the way a person exhibits pieces of their cultural identity through language, dress or conversely a person can deduce some inkling of a person's identity. And also, the facts of history speak a constant reminder of a person's race, ethnicity, etc. Though it is not always the case, according to Denzin, that one of the six selves is dominant; I have made that inference to explore the implications of having a dominant "self."

\section{Precusor to Communicating One's Self}

When considering the phenomenological self, it is important to approach it as an abstract sense of self. It is abstract because it is not necessarily concrete or quantifiable for all persons. Instead the phenomenological self is a quality of one's self because it entails a conscious experience. Moreover, the phenomenological self is an inner stream of consciousness that lends to an acknowledgement of who you are and what you are experiencing. In an effort to make this layer of self concrete, we can deduce that the phenomenological self is an internal and conscious collection of thoughts and acknowledgments that one is actually experiencing "self" within a social interaction (e.g. self-awareness).

The interactional self is the most concrete of all layers of self because it implies a performance. One perspective of sociology is the dramaturgical approach; it encompasses all persons as actors who perform social interactions that are guided by social norms. However, such an approach is not simplistic because there are many dynamics within the social norms that impact our interactional self. These dynamics can include power relationships, expectations and limitations of one's role within a social interaction, implications of race, gender, and other differentiating aspects.

The linguistic self, as described prior, is actually very simplistic. This layer of self is about communicating one's self through language verbal and non-verbal. This layer entails the power of language and the nuances of language including proper/formal language, profanity, slang, overall clarity, the use of proper tenses/function (i.e., past, future, imperative), and how the context of the social interaction may cue a certain use of language.

The material self as previously defined is the self as an object. Again we can use the dramaturgical approach to see that one's material self is the object(s) that you see and interpret about the individual. The idea here is to express a self that consists of all the material objects that one can call his or her own at that moment in the social interaction. 
The ideological self is very concrete. It is self-explanatory to express one's self and also, interpret an individual based on the broader cultural and historical meanings that surround the definition of the individual in a particular group or social situation.

Lastly, the self as desire indicates experiencing one's self through the physical shell of one's body; the flesh, one's sexuality/ sexual orientation and the bodily presence of others surrounding the individual.

Denzin's theory of 6 layers of self suggest that we communicate a lot about ourselves in different ways (layers) all the time; notice when one of the six layers of self is dominant, or ask rhetorically what do one's material objects say about the person? Furthermore, what about the linguistic ability, choice, dialect, etc that a person utilizes, does it not speak of their culture and identity? The introduction and this section function as tools or ways of how to "play the game." The context of "the game" is predominantly white collegiate institutions and our "players" are the students (black students in particular).

\section{Colorism}

Hochschild and Weaver (2007) define colorism as "the tendency to perceive or behave toward members of a racial category based on the lightness or darkness of their skin tone," in a piece titled The Skin Color Paradox and the American Racial Order. And ironically, when considering whiteness in America, there is an inclusive property that is only differentiated by one's ethnic pride/ethnicity. The differentiation or manifestation of colorism in a white population is often based on one's definitive measures to express their ethnicity. One may speak a European language and/or identify with other pieces of a certain culture. Yet, the irony is that such an individual is still perceived as white. The lines of separation among white culture are usually ethnic. There is a tacit pride in having a European descent with strong heritage and culture, yet adamantly denying being a white American. Please consider the quantitative and simplistic research conducted at a predominantly white collegiate institution.

\section{Review of Literature}

Hochschild and Weaver (2007) define colorism as "the tendency to perceive or behave toward members of a racial category based on the lightness or darkness of their skin tone." Denzin (1992) believes there are six "layers of self" within a person; such as the ideological self, which is a perception of self that encompasses the larger historical and ethnic background of a person. This speaks to the social impact that race/ethnicity can have on an individual student in a predominantly white collegiate institution. Furthermore, cultural appropriation is "the adoption of some specific elements of one culture by a different cultural group." This explicitly confirms that there are in fact, social dynamics occurring when white students and other diverse students, such as AfricanAmericans are socially involved together in a social context or organization like a school setting. However, there are types of negative interactions or social norms that impact the social dynamics of students in a predominantly white collegiate institution. For example, one dynamic is known as colorism, which is the preferential/discriminatory treatment of a person of color based on his/her skin tone. Kerr (1969-) states: "the first 'complexion tests' were racial confrontations executed by whites to keep fair blacks from 'passing into' white organizations, institutions, and even white families." However, how is a student affected by colorism? How is a minority student supposed to exist/thrive in such an environment? How can one play this game? Notice the parameters of the "game", as Delgado and Stefancic (1997) write, "whites have difficulty perceiving whiteness, both because of its cultural prevalence and because of its cultural dominance." This is another major theme regarding this action research project: whiteness. Delgado (1997) writes, "privileged identity requires reinforcement and maintenance, but [also] protection against seeing the mechanisms that socially reproduce and maintain privilege is an important component of the privilege itself." Garner (2007) writes that:

[whiteness] is the framing position: a dominant and normative space against which difference is measured. In other words, white is the point from which judgments are made, about normality and abnormality, beauty and ugliness, civilization and barbarity. Whiteness has come to be represented as humanness, normality and universality: 'whites are not of a certain race, they are just the human race.' If white is human, then all else requires qualification: everything else is deviant. 
Noteworthy research shows that stereotype threat is a major factor for students of color in relation to white students in a predominantly white collegiate setting. Stereotype threat as Steele (1999) defined, is "the threat of being viewed through the lens of a negative stereotype, or the fear of doing something that would inadvertently confirm that stereotype," that is, the threat of being labeled deviant and fulfilling a stereotype in relation/contrast to whiteness. So what is the solution? The notion of communicating one's self comes from a deep level of sociological theory yet it can be reduced into a basic, simple understanding of what it means to "play the game." Notice George Herbert Mead's concepts of play, game and the generalized other.

Mead suggests that as people grow they learn to adopt roles and essentially childhood games of playing house, cops and robbers, hide-and-seek, etc. are similar to the ways that we are socialized. The significant difference is that the "rules" or norms that are involved in how we play (or socialize) change, hence so does the game.

Dubois (1996) tells us that minorities, specifically Blacks, experience a double-consciousness: "A peculiar sensation, this double-consciousness, this sense of always looking at one's self through the eyes of others, measuring one's soul by the tape of a world that looks on in amused contempt and pity. One ever feels his twoness,-- an American, a Negro; two souls, two thoughts, two unreconciled strivings; two warring ideals in one dark body..." Researchers like Dubois, tell us that minorities are aware of their skin tone and the implications surrounding that. Additionally, Heckstall (2009) suggests that there is a consequence of having a "Black identity"; there are consequences to the social issues of colorism and race in a predominantly white collegiate institution. For example, a minority student may feel the social effects of deviance. First acknowledge that the larger context is predominantly white and Garner writes that whiteness is a framing position. Thus, all those who differ from this frame of reference deemed whiteness, are considered deviant. And at times there are negative attributes that are ascribed to being deviant.

So why is colorism important? If the average educator/ school administrator can attest one thing about school life, it is the fact that students are developing socially and experience social issues and setbacks while simultaneously progressing with their learning and student achievement. Student achievement is one issue among legislators, teachers, parents and probably students that is on the up-and-up, meaning that nearly everyone is actively concerned or involved in increasing student achievement. One significant problem with student achievement is the lasting divide between minority students and white students; this is known as the Black-White Achievement Gap. People may generally think that the Black-White Achievement Gap exists because of lack of motivation from students, bad teachers, lack of academic preparation, natural intelligence, discipline issues, etc. Yet, it is common knowledge that bullying exists in school and we know that a victim of bullying may struggle in school both socially and academically because the issue of bullying has an impact. Using the same logic, other social issues affect students in a variety of ways. Thus, discrimination or more specifically, colorism is a social issue that too affects students and one might infer that it indirectly affects student identity and achievement; Heckstall's (2009) expands on this notion.

\section{Methods and Procedures}

As previously discussed in the review of the literature, colorism is essentially the preferential (or discriminatory) treatment towards member of a racial group based on the lightness (or darkness) of their skin tone complexion. As such, this action research aims to answer two very important questions: are non-white students aware of colorism at a predominantly white collegiate institution?Is colorism a significant problem as indicated by intragroup division, prevalence or another impact upon student? When framing these research questions or purpose of the study, it is important that the reader knows how these questions can advance or change educational practices. Hence, colorism is a social issue that is detrimental to a person's self-esteem, issues of prejudice, his/her social lives in terms of self-segregation and truly a deeper issue of identity. The two specific research questions are intended to assess that first non-white/minority students are in fact aware and/or experience colorism; this will indicate that colorism exists in this context. Secondly, the next research question is designed to alert the reader to the possibility that colorism is significant enough to the extent that it is problematic to this sample.

The sample population was derived both randomly and purposefully. The respondents are specifically non-white students, yet the respondents are random students on a predominantly white college campus. The 
specific setting is best described as a predominantly white college campus in the central part of Connecticut. The statistics of the population as a whole is reported by the admission office as: $52 \%$ women, $9 \%$ Black or African American, 2 \% Bi-racial, 3\% Asian and 74\% white students. The subjects were targeted from a minority support group on the campus and guaranteed that subjects were non-white students of the college. Participants were ensured of confidentiality and asked to complete the survey. I administered the survey to many respondents both male and female, although differentiating the results from male/female, class year, etc. are not significant nor fitting to the two research questions.

The surveys were administered during group settings and collected first hand. The survey is anonymous and because the survey was completed during a group environment there is less probability or identifying such during the collection process. After a participant completed the survey there were placed in a pile and collected all at once without any indication to who completed the survey or not and in what order. Moreover, the subjects were unfamiliar to the researcher, which contributed to the inability to identify a participant and his/her survey. The specific ways of analyzing the surveys include comparing the first two questions on the survey; notice that although a subject may have never experienced colorism while at school, the second question is a subtle way of evaluating that the student is "aware" of colorism which can still answer the first research question. The second method of analysis is using a direct question to assess whether students think that "colorism" is significant in the specific context. This question is also correlated to the last two open-ended sections of the survey, which can potentially signify patterns, differences, etc. as these relate to a solution for administrators and best practice.

Results: Table of Respndents

\begin{tabular}{|c|c|c|c|c|}
\hline $\begin{array}{l}\text { R1-12 indicate a specific } \\
\text { subject's response }\end{array}$ & $\begin{array}{l}\text { Response to } \\
\text { Q1: Yes }\end{array}$ & $\begin{array}{l}\text { Response to } \\
\text { Q2: No }\end{array}$ & $\begin{array}{l}\text { Question 4: Do you } \\
\text { think "colorism" is a } \\
\text { significant issue at a } \\
\text { predominantly } \\
\text { white school? }\end{array}$ & $\begin{array}{l}\text { Aware? (This is } \\
\text { deduced by } \\
\text { comparing } \\
\text { questions } 1 \& 2 \text { on } \\
\text { the survey) }\end{array}$ \\
\hline \multicolumn{5}{|l|}{$\begin{array}{l}\text { Question 1: Have you ever/ } \\
\text { Do you experience "colorism" } \\
\text { while at school? }\end{array}$} \\
\hline R1 & & $x$ & No & Yes \\
\hline R2 & $x$ & & Yes & $\mathrm{N} / \mathrm{A}$ \\
\hline R3 & $x$ & & Yes & $\mathrm{N} / \mathrm{A}$ \\
\hline R4 & $x$ & & No & $\mathrm{N} / \mathrm{A}$ \\
\hline R5 & & $x$ & Yes & Yes \\
\hline R6 & $x$ & & Yes & $\mathrm{N} / \mathrm{A}$ \\
\hline R7 & & $x$ & No & Yes \\
\hline R8 & & $x$ & No & Yes \\
\hline R9 & & $x$ & Yes & No \\
\hline R10 & $x$ & & No & $\mathrm{N} / \mathrm{A}$ \\
\hline R11 & & $x$ & No & No \\
\hline R12 & & $x$ & No & No \\
\hline
\end{tabular}

The results show a mix of patterns and even a couple interesting outliers. The relevant research questions are: are non-white students aware of colorism at a predominantly white collegiate institution? And is colorism a significant problem as indicated by intragroup division, prevalence or another impact upon student (s)? To determine whether a respondent is aware of colorism, that respondent would have either answered positively to a personal experience with colorism or answered positively to discussing colorism among his/her friends. The most pertinent results that relate to the research questions include that $75 \%$ of respondents are "aware" of colorism. Also, important among this sample is that $16 \%$ (2 out of 12 ) respondents were actually white students, which directly impacted the statistic of awareness and whether or not a respondent felt that colorism is a 
significant problem. The second most pertinent result answers the second research question. And thus, nearly half of the subjects thought colorism is a significant problem at a predominantly white collegiate setting; more specifically 5 out of $12,41 \%$.

The other method of dissecting the second research question involves analyzing the open-ended sections of the surveys. Notice that the second research question is two-fold: firstly, is colorism a significant problem and secondly, does colorism lead to intragroup division, prevalence or another impact upon the student. Hence, the following table categorizes individual responses from the survey into larger themes. The specific question where these excerpts are taken from is: list a few bullet points on how a person could counter/defeat colorism.

\begin{tabular}{|c|c|c|c|}
\hline Multiculturalism/Equality & Discussion & Self-Obligation & Other \\
\hline "Look at others as equals" & $\begin{array}{l}\text { "...talking about it } \\
\text { (discussions)." }\end{array}$ & $\begin{array}{l}\text { "Avoiding negative } \\
\text { peers" }\end{array}$ & $\begin{array}{l}\text { "There is no way to } \\
\text { defeat it..." }\end{array}$ \\
\hline $\begin{array}{l}\text { "Don't accept that there is } \\
\text { a significant difference in } \\
\text { color" }\end{array}$ & $\begin{array}{l}\text { "asking people to stop } \\
\text { talking about their skin } \\
\text { tone as if it is negative" }\end{array}$ & $\begin{array}{l}\text { "Think more of what is } \\
\text { on the inside..." }\end{array}$ & "live through it" \\
\hline "promote anti-colorism" & & $\begin{array}{l}\text { "Avoid ...a certain crowd } \\
\text { that has negative } \\
\text { feelings.." }\end{array}$ & "Fight" \\
\hline $\begin{array}{l}\text { "not declare a side... team } \\
\text { dark skin or team light } \\
\text { skin" }\end{array}$ & & $\begin{array}{l}\text { "..embrace their skin } \\
\text { tone.." }\end{array}$ & "go to Africa" \\
\hline \multirow[t]{3}{*}{ "treat all people equally" } & "education" (x2) & "rise above stereotypes: & "die" \\
\hline & $\begin{array}{l}\text { "people to bring more } \\
\text { awareness to it." }\end{array}$ & "ignore comments" (x2) & \\
\hline & & $\begin{array}{l}\text { "point it out when it } \\
\text { happens" }\end{array}$ & \\
\hline
\end{tabular}

\section{Discussion}

In conclusion, the results show that the majority of minority students recognize colorism as a problem. Note that colorism is both a problem for the individual student and the school at large is accountable to some degree that students are experiencing this social issue. This topic of colorism at a predominantly white college is important because it is a two-fold issue. Notice that when the individual experiences colorism, they feel that it is a problem; in fact, $41 \%$ of respondents agree that colorism is a significant problem. And secondly, teachers, administrators and the leaders of the school may unintentionally contribute to colorism. From this end, colorism looks differently: in the classroom, a teacher may show preferential treatment, educators may not be privy to how colorism may connect to a student's self-esteem of self-efficacy in certain areas of school life, teachers may not do enough to promote multiculturalism, or there may be some degree of "racial profiling" especially if a certain group of students is consistently targeted for disciplinary action. In an even larger context, school leaders are accountable for their school culture. As such here are a list of implications for practice:

- Administrators should promote multiculturalism; this is strongly supported by the responses from the survey who believe tolerance and equality can resolve the problem

- Students should develop their self-esteem along with a teacher's help because the data shows that the individual student is very obligated to deal with the social issue of colorism

- In terms of discipline or scheduled interventions, there should be opportunities to discuss colorism and deconstruct stereotypes; perhaps this fits with faculty support of student groups, Black History Month, bullying issues, etc.

- $57 \%$ of respondents did not experience colorism but were "aware" of it as evidenced that these respondents discuss colorism among their friends, hence schools should take preventive measures to deter colorism and promote a strong school culture more towards equality and common experiences

- The fact that a respondent suggested "going to Africa" or to "die" in response to colorism, indicates that at an extreme this topic is a controversial issue with serious ramifications 
The limitations of this research finding include the fact that the sample size was not large enough. Although the survey, its results and the research questions all correlated to prove a valid study. Another limitation is the fact that there is no indication of the perception from teachers, administrators, etc. regarding colorism, which directly limits how much this research can suggest about colorism in the school environment versus the individual experience. Hence areas of future/further research should include whether or not colorism affects student self-esteem and measure that effect. Also, if and how does the social issue of colorism impact student achievement and with expounding upon the techniques to counter colorism in the educational arena. By researching the solutions to colorism, this can inform educators for best practices and also outline a larger systematic approach to schools where colorism is more prevalent. Further research can also intensify the efforts of this action research, by conducting more thorough ethnographic studies of students versus administrators and also gathering the "outsider's perspective" to this issue. Perhaps future research should include the opinion of people who engage in "colorist" behaviors and determine the reason for such; this could provide a better understanding of how significant colorism is.

One major reflecting point of this action research project is the fact that colorism exists in various ways on college campuses and it has an impact on students. Notice the observation/opinion article by William Jackson, where he observed a group of women on an HBCU (Historically Black College/University) campus who were speaking very "colorist" insults about other females who were not present. The article continues to mention that certain sororities and fraternities use a "brown-paper=bag test" to divide and decide whether certain AfricanAmericans can be admitted into the social organization. It also speaks more about the history of colorism and the utter disgust that it still occurs even after the Civil Rights Movement. And too, there are specific examples of people who are working to counter colorism.

Ultimately, the most direct conclusion that this action research shows is that colorism is a problem at schools. Yet, the ways in which school specifically work to eliminate colorism, then consequently in general, there will manifest more ways to eliminate other prejudices and student social issues.

Looking at either example as extremes of the Black-White spectrum, it is clear that America has subconsciously agreed to a happy and ambiguous neutral that exists as an ideology and a preference. This is substantiated by Hochschild and Weaver's work as they assert, "skin color is associated with individuals' preferences as well as their outcomes. With some exceptions, most Americans prefer lighter to darker skin aesthetically, normatively and culturally. Film-makers, novelists, advertisers, modeling agencies, matchmaking websites - all demonstrate how much the power of a fair complexion, along with straight hair and Eurocentric facial features, appeals to Americans." Colorism is an American ideology.

But how does colorism necessarily operate within whiteness? Note that "colorist" prejudices substantiate the color line. The "color line" definitively separates whites from the collective black, based on skin tone. Ashton (2001) states "the color line...was a line that had many different configurations [such as a figurative horizon]. "The horizon represented a shifting line meriting neither the guileless optimism of a sunrise nor the resigned nature of sunset." However, as colorism and the mulatto race expands, the color line becomes blurred. It is possible for a light-skinned black person to actually "pass" as white. In fact the very phrase: "passing as white" inherently, indicates passing over the color line and gaining entrance into the white collective. And too, it seems that there are other attributes that alter the perception of a "black" individual and enable the "black" individual to pass the color line, namely money, cultural capital, social capital and how you communicate your self through Denzin's six layers of self.

The color line is essentially a law of deviance. One meaning of deviance implies a tacit standard from which others vary. Therefore, the more that the color line is blurred as stated, the more integration occurs. Moreover, the more integration occurs, the more cultural appropriation manifests itself. In which case, the color line is compromised. In other words, the more blacks integrate with whites, the more said blacks manifest cultural appropriation and vice versa. Cultural appropriation is "the adoption of some specific elements of one culture by a different cultural group." Yet, this is how colorism operates within whiteness: whites can walk up to the color line, cross it and/or retreat and culturally appropriate. Furthermore, whites can pass the color line and not lose a sense of the meaning of their whiteness. Notice that this is substantiated by Kerr (1969-) when she states "complexion discrimination is the implosion of racism - the internalization of slavery and Jim Crowismwherein the profound and enduring residue of black social quarantine resides. Because white America went to such lengths to (supposedly) remain distinct and "purely" white, comparable demarcations of the margins and 
borders of race have been tested internally as part of rhetorical curiosity about whether whiteness can work for blacks as well as it works for whites. It is a simple truth that the caste system in black America depends on racism and race barriers, from which it draws its rules, customs, and norms."

Thus, colorism is an obstacle. Colorism affects blacks and whites. Notice that Hochschild and Weaver (2007) state that "also like racism, colorism can be thought of as either unidirectional (only those with power and status can exhibit it) or multidirectional (people of any one skin shade can denigrate or subordinate people of another)." Hence, there is a duality of authenticity and race-trading that acts as a constraint to those of Black identity actually communicating one's self. Notice if the Black student does not express an identity that is somewhat congruent to the hallmarks of Blackness then others will doubt the authenticity of that individual's Blackness, as indicated in the introductory questions of interest. And with this growing doubt, when communicating one's self that is not aligned to a homogenous Black identity, there becomes a notion of racetrading or trying to act white. The apparent catch-22 is evidence that colorism is an obstacle.

Colorism has historically been an obstacle. Kerr (1969-) states "the first 'complexion tests' were racial confrontations executed by whites to keep fair blacks from 'passing into' white organizations, institutions, and even white families." "All of these 'tests' depend on the presumption that whiteness is a conclusive category." For instance, "from the 1920's until the 1940s, white establishments occasionally employed blacks to work as 'spotters' who stood at the entrance of white establishments to keep blacks who appeared white from passing into 'white only' public places." Furthermore there are other types of tests such "as a condition of [their] social acceptance of me, require[s a black student] to prove my blackness by passing the Suffering Test." These tests are symbolic of scenario 4 from the introduction and really all of the introductory scenarios. Hence, I posit that the piece of brilliance is to use the mechanism of colorism against itself. The identified 6 layers of self as a precursor to communicating one's self stand to reason that Black students can in fact play the game with an advantage. This advantage is exemplified in knowing the answer to the first 3 introductory scenarios. For example, with scenario one: the black student must remember how perhaps a traditionally white fraternity may/actually perceive the black student. Thus the black student has to adapt.

\section{Introducing the White Mirror Experience (WME)}

The word mirror figuratively implies "something regarded as accurately representing something else." Additionally, the word mirror figuratively implies an ability to "correspond to" something or someone. Now, the White Mirror Experience is the realization that the adaptation of one's blackness can mirror whiteness.

The White Mirror Experience is essentially such: the color line is metaphorically the mirror, which splits the spectrum between Black and White. And as members of either end of the spectrum look at the mirror in the middle, colorism as a mechanism thus portrays two different reflections in this "mirror". The ability to assert and maintain the authenticity of one's own blackness involves expressing an identity congruent to the mass cultural hallmarks, group norms, behavior, speech and even stereotypes of the ideological self. Yet, the White Mirror Experience involves being able to present a personally composed identity that is indicative of the meanings of its attributes. How do you communicate yourself when each layer of self is being evaluated and simultaneously maintain cultural/ethnic authenticity? The idea is to present a personally composed identity that is independent of the generalizations of one's collective social group. Hence, Dubois (1996) wrote that there is a "world that looks on in amused contempt and pity," on the black individual's double-consciousness as the "Negro feels his twoness." Essentially, a black student has to maintain his/her black culture and represent the black community/culture very well to an exemplary standard, which does not make the individual any "less black" but more so "notably black." This is done through communicating one's self effectively, as the 6 layers of self indicate a precursor to communicating one's self; henceforth is how to communicate one's self, within the context of predominantly white collegiate environments.

\section{Communicate One's Self}

The notion of communicating one's self comes from a deep level of sociological theory yet it can be surmised into a simple understanding of what it means to "play the game." Notice George Herbert Mead's concepts of play, game and the generalized other. 
Mead suggests that as people grow they learn to adopt roles and essentially childhood games of playing house, cops and robbers, hide-and-seek, etc. are similar to the ways that we are socialized. On a deeper level, Mead's notion of play can be encompassed as assuming a role and using a set of stimuli that is imposed on (or known and utilized by...) the individual in order to elicit the sort of responses that the stimuli call out in others. As simple as it is for children to understand and utilize the role "cop" and set of stimuli it takes to play cops and then elicit a response from "robbers", so much so is it necessary for persons to adopt significant and intricate roles and consequently command the set of stimuli needed to elicit the appropriate responses that the set of stimuli call out in others. Simply put humans are very social creatures in various ways. Thus to understand socially how you can adopt a role by communicating certain stimuli in order to affect another's response is purely acting. But this form of play is a concept for the black individual to collect and define his/her own set of stimuli, thus making him/her unique and better understood. Hence one must communicate one's self and begin to play.

Mead also organizes the field in which we play or rather the game. Mead suggests in summary that as one plays, that individual must organize the various beings/roles along with the social relationships between such to build up the character of the individual. In other words, if and when an individual in a group of more exists, then the one person must organize the social relationships between his/her company, in order to build his/her own character in the social interaction. This implies that there are rules to "play the game"; one must understand and utilize the social relationships given any number of factors including gender, race, age, etc. in order to play. And again, you must communicate who you are within the game. For instance, if a "black" individual wants to play in the game of predominantly white collegiate institutions then the social relationships are important to observe. This level of understanding may seem inherent to most but it appears to be a buried treasure to those of black identity who struggle to communicate themselves.

The last part of the concept to communicate one's self is where Mead integrates the play and the game and enlightens one to respect the generalized "other." Essentially, one must not only take the attitude of individuals towards him or herself and the attitude towards one another, but also one must take their attitude towards the aspects of the common/shared social activity, which as members of a social group or organized society, they are all together engaged. For example, (scenario five from introduction) when people constantly ask a black student at a predominantly white collegiate institution, whether or not they actually go to school there, it shows that the black student is not playing the game. Remember whiteness has an inclusive property; therefore the identity/attitude towards one another must communicate inclusion. Yet, the black student stands out for some reason and immediately causes deviance, thus disrupting the common/shared activity. Hence, people ask "do you go here?"

All of the five scenarios in the introduction have been answered, but undoubtedly at the root of this analysis, it shows that the identity issues of black students are a factor in the Black-White Achievement Gap. In order to bridge the understanding, you have to infer the complications that these social identity issues bring to the black student in a predominantly white collegiate setting.

\section{Conclusion}

The way we socialize from backyard BBQs to elite institutions of higher education as well as the mechanisms that affect how we socialize, both have an influence on us all. Denzin's six layers of self is a template of the way we socialize and colorism is a mechanism that affects how we socialize. And clearly, this article shows there is an influence on individuals in the context of predominantly white collegiate institutions. How the pinnacle reason and logical deduction from this article is for black students to use colorism against itself, achieve one's goals within higher education, maintain character/cultural ethnicity and reflect positively for one's cultural ethnicity.

There are subtleties to the progression of each concept in this article, along with overlooked connections of all the material. For instance, in regards to the "white mirror experience," there is a profitable approach to this concept. Logically, if the black individual communicates any degree of the dominant culture or the social privileges attributed to such, then the "white mirror experience" is not a transformation, nor is Dubois' 'doubleconsciousness' a burden. Instead it is concept to be manipulated at the discretion of the black individual. The white mirror experience then becomes a feather in one's hat; the ability to adapt is obviously a skill when socially enduring the survival of the fittest. 
While colorism exists coupled with the need to communicate one's self through the six layers of self equates to essentially playing the game.

\section{References}

Denzin, Norman (1992). Symbolic Interactionism and cultural studies: the politics of interpretation. Oxford,UK and Cambridge,USA: Blackwell Publishers.

Dubois, W.E.B. (1996). The Souls Of Black Folk. New York: The Modern Library.

Stuhr, John J. (2000). Pragmatism and Classical American Philosophy. New York, New York: Oxford University Press, Inc.

Delgado, Richard \& Stefancic, Jean. (1997). Critical White Studies: Looking Behind the Mirror. Philadelphia: Temple University.

Garner, Steve. (2007). Whiteness: An Introduction. USA and Canada: Routledge.

Mead, George Herbert. (1998). The Self. In Macionis, John J., and Nijole V Benokraitis. Seeing Ourselves: Classic, Contemporary and Cross-Cultural Readings in Sociology (pp.80-81). Upper Saddle River, New Jersey: Prentice Hall, Inc.

Steele, Claude M. (1999). Thin ice: Stereotype threat and black college students. The Atlantic Monthly, 284.2, 3

Heckstall, S.E., and Rosenthal, R. (2011). Higher Education: Black Identity and a Fearful "Mindset." Journal of Educational Opportunity, 26 (1), 36-45. 